[Hall, C. (1998). The National Qualifications Framework Green Paper: What Future for the Framework? New Zealand Annual Review of Education, 7, 29-57]

\section{The National Qualifications Framework Green Paper: What Future for the Framework?}

\section{CEDRIC HALL}

\section{Abstract:}

This paper examines some of the proposals in the Government Green Paper A Future Qualifications Policy for New Zealand. An analysis of responses to the Green Paper indicates a strong division between those closely associated with industry training and those responsible for the provision of general and professional education. The position taken in this article is that the Green Paper is a major advance on the current National Qualifications Framework (NQF), but that the proposals are unlikely to be implemented successfully without greater mutual understanding between the different sectors (industry, schools, universities and other tertiary providers). The paper identifies 17 considerations that a new qualifications structure should address if it is to be implemented successfully. Of the models suggested in publicly available responses to the Green Paper, the one proposed by Smithers (1997) comes closest to addressing the concerns raised in this article.

$\mathrm{T}$

he release of the Green Paper on national qualifications in June 1997 signalled a further attempt by the Government to establish policy which would unite industry, employers, government agencies, educational providers, and other educational bodies in support of a single national qualifications framework (NQF). The document should be commended for attempting to meet the concerns raised by many educationists with the current operation of the NQF. The purpose of this paper is to look behind some of the proposals to identify the major educational issues which need resolving if the NQF is to have a viable future.

\section{Cedric Hall}

\section{Treading the Middle Ground}

The perspective brought by the writer to this discussion reflects his academic, professional and general educational background. No attempt is made to argue an industry or Maori view - it would be highly presumptuous to do either of these. In this respect, the paper needs to be placed alongside the views of other groups.

The hugely difficult task facing the writers of the Green Paper in trying to unify opinion behind the NQF is illustrated in the following selection of extracts from some of the submissions:

The National Qualifications Framework, the Industry Training Act and Skill New Zealand were developed and introduced as part of a cohesive strategy of economic and labour market reforms to underpin New Zealand's economic growth into the next century....

The Green Paper proposals come at a critical time in the development and implementation of the current National Qualifications Framework. Retail Training New Zealand has a number of serious concerns about the proposals. It believes the proposals present a major risk to the intent and focus of the Skill New Zealand strategy. (Retail Training New Zealand (Inc.), 1997)

... the National Qualifications Framework (NQF) as it is currently configured has resulted in significant benefits to students, the public, industry, employers and the government. The NQF was established to meet real concerns and problems within the tertiary qualifications system and to address fundamental changes in our economy and society. (New Zealand Association of Private Education Providers, 1997)

We have serious concerns about the Green Paper's proposals. Some of these relate to matters to which we took exception in the TAG [Tertiary Action Group] proposals, and which appear again in this document. Others are even more serious: in particular the loss of statutory authority. The universities, however, acknowledge the Government's legitimate, indeed essential, interest in the quality of educational qualifications. (New Zealand Vice-Chancellors' Committee, 1997)

It is the opinion of this organisation that the principal difficulties with the current and proposed future direction of the NQF are: ... the $\mathrm{NQF}$ is ideologically driven, with the result that implementation, in order to fit with that ideology, has made unreasonable demands on providers. This has resulted in excessive costs which ultimately must 
be passed to students, and as a result effective delivery of quality training is channelled into non-productive activity. It has also distorted material and delivery in training, which have had to match rigid learning outcomes written to a NZQA formula rather than reflecting the reality of the workplace and the unit standard title, i.e., the cart is consistently put before the horse. (The New Zealand Institute of Travel \& Tourism (Inc.), 1997)

Many of the proposals in the Green Paper are acceptable, particularly in principle, and it is pleasing to see the major move forward from the somewhat doctrinaire stance that has operated until now. There are, however, some important omissions and weaknesses in the document; the extent of those omissions is such that the Academic Board believe that the NQF as currently described is unlikely to succeed. (Academic Board of the Christchurch College of Education, 1997)

The preceding extracts have been chosen to provide a balance between those largely supportive of the current NQF and those who are critical of the developments that have taken place over the past six or so years. It is very evident that those groups and organisations which have benefited from the NQF in respect of power and control over qualifications and training in their area (e.g., industry training organisations and private training establishments) are strongly supportive of the current NQF. This is not to say, however, that such groups have found the NQF plain sailing or that the need for modifications is not recognised (refer the submission by Retail Training New Zealand Inc. (1997)). Conversely, those groups which have lost (or stand to lose) power or control over qualifications, or who believe that the NQF is unsound pedagogically and administratively, are those who are opposed to the current NQF. The latter group includes traditional tertiary providers (many polytechnics and all universities) and secondary schools with a solid record of student achievement in traditional general education subjects. It is clear that neither side of the debate embraces the Green Paper proposals with much warmth; the attempt to ride the middle ground has as much potential to alienate all groups as it has to unite them.

\section{Personal Position of the Writer}

The final quote above (from the Christchurch College of Education) summarises my own stance. While I share with others (e.g., Woodhouse,
1997) the belief that the Green Paper is a major step in the right direction, I do not believe that the proposals can be implemented successfully without further debate on existing conceptions of how the NQF should be structured, of portability, of quality, of the importance of pedagogy (e.g., the relationship between process and outcome), of flexibility, of central control, and of compliance and teacher workload.

\section{The Green Paper Proposals}

The Green Paper sets out 14 proposals relating to the future of the NQF. The following summary highlights the key features:

- for registration on the NQF, qualifications should meet minimum criteria for quality, specify clear outcomes and be comparable with one another in terms of level and credit;

- in respect of quality, qualifications should be portable, durable, structurally sound and credible to interested groups;

- in respect of outcomes, information should make clear to students, employers and other interested groups what is expected of learners;

- outcomes should also be specified for parts of qualifications and that such information should be made available to the public but would not need to be registered;

- excellence would be recognised in school subjects which are assessed against unit standards;

- national school examinations (School Certificate, Bursary and Scholarship) would be registered as qualifications provided they satisfy the criteria for registration;

- the role of the NZQA would be modified to being that of the overall guardian of quality of NQF qualifications and would be impartial with regard to assessment methods;

- approval of qualifications would be delegated by NZQA to appropriate agencies. NZVCC would receive such delegated authority;

- NZQA would review and report publicly on the performance of approval agencies every 3-5 years;

- current NQF qualifications and other quality-assured qualifications (e.g., NZVCC approved qualifications) would be granted NQF interim approval for a three year period. 


\section{The Original Aims of the NQF}

It is clear that the Green Paper is an attempt to revive the intent of the Education Amendment Act (1990), namely, to establish a national qualifications framework which would ensure that all qualifications ... "have a purpose and relationship to each other that students and the public can understand" (Para 253 (1)(c)). The initial impetus for the development of the NQF stemmed from the perception of successive governments that educational reform should enhance New Zealand's international market competitiveness and involve industry-led developments in skills training. In designing the NQF, NZQA articulated a range of educational and equity considerations which underpinned their thinking. These included:

- the desirability of improving access to education by encouraging providers to adopt a more open and flexible approach to credit transfer and the recognition of prior learning;

- the desirability of improving the interface between vocational and general education, including the removal of artificial distinctions between the two;

- the desirability of improving the information provided to students, employers, parents, and other interested groups about available qualifications and their component parts;

- the need to establish a system of qualifications which gives improved information to students about the standards expected of their work.

The thrust of the Green Paper is still very much in line with these worthwhile considerations. However, the impact of the past six years of qualifications reforms is such that it is doubtful whether all potential participants will want to be involved. At the heart of the problem lies NZQA's model of standard-setting and the polarisation of attitudes that has developed towards it. In order to understand the directions taken by the Green Paper it is necessary to appreciate the division that the unit standard model has created.

\section{Criticisms of Unit Standards}

It is clear that the desired outcome of blending "education" and "training" is as far from attainment now as it was in the late 1980s when the need for the breakdown of the divide was strongly advocated in
Government reports (Hawke, 1988). The bases for the polarisation lie in at least two areas: first, a belief held by many educationists that the current system does not promote a true partnership between industry and education - it gives industry training organisations (ITOs) too much power and direction over providers, with insufficient attention being paid to the pedagogical aspects of education and training (Rivers, 1996; Fitzsimons and Peters, 1994); secondly, the view that the unit standard model does not generalise well to general and professional education (Elley, 1995, 1996; Hall, 1994; Churchman \& Hall, 1997; Irwin, 1994, 1997). While many industries have expressed satisfaction with the system as a basis for designing training in their areas (e.g., New Zealand Motor Industry Training Organisation, 1995), others have found the development of unit standards a tortuous process with considerable dissent about the value and general applicability of the resultant standards (see, for example Alan Hall (1997) on teacher education; Neyland (1996; 1997) on senior secondary school mathematics).

The main criticisms of the model include the following:

\section{Pedagogical and educational concerns}

- the negative impact on course coherence of separating the specification of standards from curriculum development and course design;

- the failure to acknowledge openly the complex nature of most educational and vocational standards and the difficulty in specifying such standards in an easily interpreted form;

- the failure to recognise the impact of process on outcome and the implications of this for interpreting educational standards;

- the "neo-behaviourist" and reductionist nature of the unit standard model and its unsuitability to most general and professional educational contexts;

- the increasing emphasis on assessment rather than teaching and learning;

- the failure to include a focus on excellence;

- the failure to recognise the significance of content and context in assessment of student work and decisions on credit transfer and the recognition of prior learning. 


\section{Administrative concerns}

- the array of cumbersome moderation procedures generated by the model;

- the excessive record-keeping generated by the model and the vast bureaucratic structures being created to manage the development and implementation of the model;

- the devolved costs to users of the NQF;

- the need for greater decentralisation of standard setting for rapid handling of changes in knowledge and innovations in a subject or field (this also has a pedagogical basis);

- the excessive workloads for teachers.

Detailed discussion of the above problems is contained in Hall (1994), Gilmore (1997), Irwin (1997) and Smithers (1997). It appears that most of the criticisms have been located in general and professional education contexts, rather than in education and training as provided within existing trade and technician programmes. It is evident from industry submissions that the unit standard model is indeed meeting industry needs at the lower levels of the NQF. However, the insistence of NZQA (until recently) in driving all education and training down the unit standard pathway has probably done more to reinforce beliefs about the distinction between education and training (and general and vocational education) than it has to reduce the divide between the two. It is no coincidence that many of the submissions on the Green Paper include criticisms of unit standards, despite the request in the document that the focus should be on addressing broad policy issues rather than providing detailed "technical" analyses of implementation problems.

The proposals here are at the broad policy level, rather than a detailed technical level. There is a need to agree first on policy issues such as the goals of the NQF, which qualifications should be covered by the NQF, and who should approve NQF qualifications. These are fundamental to the credibility of New Zealand's qualifications system, and have to be decided before more technical matters can be addressed. (New Zealand Government, 1997, p. 2)

Unfortunately, it is hard to see how that the broad policy directions can be resolved without recognition of the detailed difficulties - pedagogical and administrative - that exist with the current system. It is through analyses of these that the directions for broad policy become apparent.

\section{The Major Issues}

This section focuses on six main issues which, if not effectively handled through policy development, will see the NQF continue to slide in the psyche of educationists. These issues focus on:

(i) the need to recognise the social dimension of education and training

(ii) the nature of standards-based education

(iii) the relationship between outcomes and processes

(iv) the incompatibility of unit standards with much of course-based education

(v) the limited notion of quality as elaborated in the Green Paper

(vi) decentralisation within the NQF.

\section{(i) The social dimension of education and training}

Apart from the narrowness in scope of the Green Paper in trying to avoid "technical" issues, a further narrowing is apparent in its statement of goals:

For both individuals and country as a whole, then, qualifications need to:

- be credible and useful to employers

- be readily understood by the public

- give students every opportunity to advance their learning towards the qualifications they want, throughout their lives.

(New Zealand Government, 1997, p. 10)

What is significant about these goals, and significant about the Green Paper overall, is the absence of any recognition of the social dimension of education. Emphasis is almost exclusively on the economic dimension - any reference even to the benefits accrued to individuals is couched within discussions of vocationalism and economic investment. The following extract is an example:

Investment in developing skills and knowledge whether by individuals, firms or the Government is therefore critical. Students and employers need a way of measuring the skills and knowledge that their investment has achieved. (New Zealand Government, 1997, p. 3)

Policy development which ignores the significant interface between the personal, social and economic dimensions of education is unlikely to 
fulfil the goals adequately of any of these dimensions. This point is firmly recognised in the submission on the Green Paper by the New Zealand Vice-Chancellors" Committee (NZVCC):

However a significant proportion of university qualifications are not principally vocational.. Nowhere in the Paper is there any recognition of qualifications as education. The gaining of employment as a direct outcome is not the sole aim of education. Education is of general benefit to the individual and to society. (NZVCC, 1997, p. 7)

This point is addressed in more detail by Codd et al., (1995) and Fitzsimons and Peters (1994). The NQF needs to genuinely reflect the broader goals of education and training if it is to successfully achieve its stated aim of unifying all qualifications under the same structure.

\section{(ii) The nature of standards-based education}

The establishment of the NQF was heralded by NZQA as a major paradigm shift for educational assessment (Barker, 1995). The intention was that all publicly-funded education and training should be based on the notion of the "clearly defined standard". According to Barker (then employed as a senior manager within NZQA), the paradigm shift to standards-based assessment was needed to give the purchasers of education (learners, employers and the government) guarantees of what they would be buying. In criticising the previous "norm-based" approach to public education, Barker argued that it

... suited an élite approach to tertiary education but is open to

subjectivity.... The morality of the norm-referenced approach is also

dubious. "Only some can learn" is an unstated premise. (Barker,

$$
\text { 1997, p. 21). }
$$

The Barker paper is remarkable, less for its aggressive attack on norm-referenced assessment, than for its failure to acknowledge the well documented difficulties associated with standards-based education. "Subjectivity" is a problem with any standards-based system of assessment, just as it is with norm-based assessment. This is why such systems place heavy reliance on moderation as a tool for aligning teachers' interpretations of a standard. Many critics of the NZQA position support the move towards giving students, employers and the community better information about the content and objectives of an educational programme, but challenge as misleading the claims that such information can be identified in the form of "clearly defined standards" (Elley, 1995; Irwin, 1994; Smithers, 1997; Tuck, 1995).
Standards-based education can in fact be given greater emphasis in traditional educational contexts by employing sound assessment practices (Hall, 1997). These practices include: giving students clear information about the content and objectives of a course (a focus on both processes and outcomes); designing assessment tasks which relate directly to the content and objectives, and which integrate the different parts of the course; specifying the assessment criteria which will be used to judge student work on these tasks; giving this information to students before they undertake their work; taking steps to ensure that different teachers/markers apply the criteria as consistently as possible (this may involve training of markers and moderation of grades); and giving students useful feedback on their performance. However, these practices need to recognise all of the following points:

- the specification of clearly defined performance standards, including assessment criteria, is extremely difficult in most educational contexts;

- the development and/or application of educational standards inevitably involves some element of norm-referenced assessment;

- the effort and cost needed in making clear an educational standard in writing quickly reaches a point where the law of diminishing returns takes over - additional effort is not matched by educational benefits.

A more realistic approach to standards-based assessment (compared to the unit-standard route) can be introduced into educational programmes for both formative and summative purposes. The way forward is not to dismiss either norm- or criterion-referenced approaches to assessment because of their respective weaknesses; rather, it should be possible to select assessment tasks and "referencing" approaches to match the purpose and the nature of the task. Good assessment practice, not a rigid adherence to a particular mode of assessment, is the principal consideration. It would appear that this is the view which has been reached by the writers of the Green Paper, and this largely explains the proposal that NZQA should become impartial in regard to assessment methods.

\section{(iii) The relationship between outcomes and processes}

The Green Paper has placed considerable faith in the notion of "outcomes". Interestingly, it has provided a definition which effectively reduces the concept to just about any kind of statement which gives 
useful information to students, employers and the public about what is expected of learners: “... acceptable outcome statements could include 'purpose statements', 'objectives', 'process objectives', 'standards' or 'learning outcomes'”. (New Zealand Government, 1997, p. 21)

Such a liberal interpretation of the notion of an "outcome" is to be welcomed, although another term might be more appropriate to describe the range of possible statements that now qualify. In the end, the format for telling learners what is expected of them is less important than the quality and clarity of the information provided. However, the flexibility provided by the Green Paper will require a good deal more explanation if it is to be accepted by the defenders of the current NQF. At the university level, it has been argued that the interpretation of an educational outcome cannot be separated sensibly from the course content and educational processes generating it. The evidence for this conclusion came from analyses of the different interpretations that could be given to a particular statement of outcomes, the different content that could be the focus of study for these outcomes, and the different teaching methods that could be used, each of which would have a different impact on the mode by which students learn. "The open-ended nature of knowledge and learning is something which a statement of learning outcomes can never capture with precision" (Hall, 1997, p. 82).

Learning outcomes are useful for giving students a sense of direction; they are much less useful in describing with precision what a student will achieve. If utility is the test, it is very likely that students will find a statement about the course content and processes just as valuable for giving them the direction they need. (Hall, 1997, p. 83)

The above paper also challenged the Ministry and NZQA to identify the research and philosophical bases for outcomes-based education. The following extract summarises the reasons for that challenge:

To base an entire national educational structure on such a foundation [outcomes-based education] surely requires a solid research and/or philosophical basis which is consistent with every form of education to be linked with the NQF. I can accept that some industry groups which operate within a highly specified knowledge and skills domain might choose this approach for defining the competencies expected of their trainees. But why is this approach uniformly appropriate for subjects such as history, mathematics, English, drama and science, or for professions such as teaching, accountancy, law and architecture? The point I want to make is that for a particular educational approach to be adopted nationally, it must be demonstrably the most suitable way forward for all levels of education, all subject/professional areas, and all qualifications to which it is intended to relate. (Hall, 1997, pp. 83-84)

If the basis of the outcomes requirement of the Ministry of Education is simply to ensure that customers receive clear information about programmes and courses, so that they can make more informed choices, then the system should emphasise quality and clarity of information, not the form of that information. Any requirement to follow a particular model is in danger of overstepping the boundary between centralised control and local expertise. Central requirements should relate to the procedures by which institutions assure the quality of their programmes - this will give the Government the assurances they need about their "investment" in education - rather than require institutions to follow an educational model which may be inappropriate to the content and processes to be used. Quality assurance methods exist (quality audit, for example) which challenge institutions to justify the suitability of their practices.

The same paper also questioned any requirement that the outcomes for the separate components of a programme (qualification) be registered on the NQF. The Green Paper appears to be in accord with this view by proposing that outcomes for components be publicly available but not registered.

It [the proposal] recognises that providers need the flexibility to modify programmes as knowledge and needs change, and that re-registering component outcomes can be onerous. It also recognises that, with over 20,000 components of qualifications already established, the task of approving each individually would involve substantial compliance costs. To limit such costs, it is proposed that outcomes for components should be publicly available to students and employers, but do not need to be individually registered. (New Zealand Government, 1997, p. 22)

The intended flexibility of the Green Paper is praiseworthy, but surely it is the role of the institution to identify what information it should make available, its format, and how it should be communicated and marketed. For example, if an institution finds that "outcome" statements are not the best way to explain what its programmes and courses are 
about, then it should not be compelled to use this format. Quality assurance methods, which challenge institutions into explaining their practices, serve both quality control and quality enhancement functions and are more appropriate for guaranteeing quality.

\section{(iv) The incompatibility of unit standards with course-based education}

Unit standards were intended by NZQA to be the building blocks of qualifications. A unit standard is a specification identifying the outcomes (elements) and performance criteria that learners must meet in order to accumulate credit towards a qualification. The point that has been frequently made is that unit standards are not units of learning they are assessment targets which learners must achieve.

Since 1992, NZQA has established over 200 groups to develop unit standards and qualifications for their respective areas. These areas have been mostly vocational in focus. The intention is that learners should be able to gain credit for what they know and can do, irrespective of how they acquire the knowledge and skills underpinning a unit standard. The learning may take place through a course, in the workplace, from personal experience, or in some other way, and it is recognised that different contexts and processes need to be available to enable learners to undertake study in a way that fits with their circumstances. Unit standards appear to be working satisfactorily at the lower levels of the $\mathrm{NQF}$ in many areas of vocational and pre-vocational training. It is claimed that the system is giving opportunities to learners who might otherwise find it difficult to break into education and training (Doyle, 1997).

However, the problems that arise from the model for typical school and tertiary course-based education are substantial. The claim by NZQA that unit standards open the door to much greater flexibility in designing teaching and learning does not stand up to close scrutiny. The theory is that educational providers can select and match unit standards to the individual needs of their students. "You develop learning programmes to suit your students. Then you select unit standards which become assessment targets for qualifications" (NZQA, 1995, p. 24).

However, a basic principle of course design is that the assessment of student performance should be coherent with the objectives, content and delivery of the course. The quotation above, which is clearly designed to create the impression of flexibility, is inconsistent with this basic principle. It is undesirable to design a course and then decide what the "assessment targets" will be. If a course is to be based around the use of unit standards, then the outcomes signalled by the unit standards must be directly relevant to the objectives (intended outcomes) of the course. The practical effect of this is that the unit standards underpinning a course will necessarily influence what is taught and even, to some extent, how it will be taught. This is consistent with the notion of coherence. However, from the perspective of flexibility - that is, being able to tailor education and training to the individual needs of learning - there are serious constraints.

The first constraint is that the complete tailoring of unit standards is not possible, because institutions simply do not have the resources to tailor courses individually in this way. The problem occurs in both schools and polytechnics. For example, most schools are able to offer two, possibly three, programmes in English/communication studies at the sixth form level. A complete "pick and mix" based around unit standards is not possible without a major increase in resourcing.

A second problem arises because of the need to report each student's performance against each unit standard undertaken. This has the effect of encouraging a checklist approach to assessment; performance criteria and elements (outcomes) become ticked off individually, thus fostering the atomisation of knowledge and learning. This has been well argued by a number of writers in the general education context (Brace, 1996; Hall, 1994; Irwin, 1994; Viskovic, 1993) and is apparent in assessment being undertaken in some industry and professional contexts as well (Murphy, 1997). The development of the intellectual skills of integration and transfer is discouraged by course arrangements which are structured to meet assessments against unit standards.

A third problem arises when students transfer mid-stream from one institution to another. Unless the course being undertaken in the first institution draws upon the same unit standards, and in the same order, as the course being offered in the second institution, a major dilemma arises. Does the student repeat unit standards that have already been studied? If not, is there institutional resourcing for the student to be given other units to undertake? And what happens over Ministry funding? A student is unlikely to be funded for undertaking the same unitstandard twice. Under these circumstances, the pragmatic approach is to do exactly what NZQA says should not be done, namely, teach directly to unit standards, one at a time. This can lead to further fragmentation of learning. 
Other major administrative and pedagogical problems are being experienced within schools and polytechnics because of the basic incompatibility of the unit standard system with course-based education. Under the unit standard model, administrative considerations often dictate educational and academic decisions - the reverse should be the case. A group of 15 secondary schools in the Auckland, Christchurch and Southland areas have adopted a trial syllabus for sixth form English, developed at the University of Waikato under the supervision of Dr Terry Locke. This includes common assessment tasks and uses a standards-based approach to assessment of student work. The participating schools have all rejected the unit standard model for teaching and assessing English. They all see improved coherence and manageability as key features of the course-based programme which they have adopted.

\section{(v) The Green Paper notion of quality}

A cornerstone of the Green Paper is that all qualifications should meet minimum benchmarks for quality. These benchmarks are defined in terms of "credibility", "portability", "durability", and "structural soundness".

Credibility focuses on clarity of purpose (the aim of the qualification is clearly stated), value of the qualification to employers and students, relevance to the needs of interested groups, endorsement by a body of national standing, and suitable arrangements for managing and reviewing the qualification. These benchmarks reinforce current criteria employed by NZQA and NZVCC for approving degrees and other qualifications. The one area of dissent, as far as the universities are concerned, is the need for endorsement by a national standards body in respect of general (academic) subjects. The universities see the creation of such bodies as unnecessary, costly and potentially a threat to academic autonomy because they vest important academic decisions about what should be taught with an external authority. The following extract from the NZVCC (1994) identifies the important difference in this respect between general and vocational education:

The NZVCC appreciates that essential differences exist between certain kinds of vocational training and university education. Unlike NZQA, the universities are not attempting to establish a single set of national standards in any subject or its sub-fields. For example, there is no reason why history as taught at Massey University should be the same (i.e., have the same objectives, lecture content, and

\section{Cedric Hall}

emphasis) as that taught at Auckland or Otago. Indeed, programme and course approval procedures followed by the Committee on University Academic Programmes, address the distinctive "flavour" of each university's proposal. Vocational training, on the other hand, may legitimately require that the skills of trainees in different parts of the country conform to common objectives and standards for employment. (NZVCC, 1994, p. 8)

Portability focuses on the notion that logical relations should exist between different qualifications and that a basis for credit transfer exists allowing students who switch programmes or institutions to gain recognition for the learning they have demonstrated to date. Exactly what is meant by "logical relations between qualifications" is not made clear in the Green Paper, but one assumes that consistency should exist in the use of degree titles and nomenclature, and that two qualifications which have a similar title and focus (BA in History, for example) should allow for students to receive appropriate credit recognition if they transfer between the two programmes. The notion of portability as presented in the Green Paper would appear to be well-founded. However, policies on credit transfer need to take account of the related literature on transfer of learning. This literature indicates that transfer of knowledge and skills across different domains requires, at the very least, similarity of the knowledge and content structures of the domains in question. Transfer is not guaranteed by a statement of learning outcomes - content and context are just as important. "Policies on credit transfer need to take account of the research.... transfer must not dictate development of educational programmes: educational content and purpose come first, the consideration of credit transfer should build on this base" (Hall, 1996, p. 289).

The notion of durability recognises that the specifications (outcome statements) related to qualifications should not require frequent modification if they are to be registered on the NQF. The issue is one of manageability for providers and teachers, and highlights the need for careful consideration to be given to the level of specificity (or generality) that is most appropriate for stating the outcomes of qualifications.

The final criterion relates to the structure of a qualification - its soundness in respect of coherence between the parts of the programme, relevance to a body of skills and knowledge, and capacity to provide flexible entry and exit points. This raises no obvious difficulties.

Taken together, the above criteria certainly provide a reasonable basis for a pproving qualifications for registration on the NQF. However, 
it should be recognised that they offer a relatively limited concept of "quality".

A qualification is an award which recognises that learning has taken place and a standard achieved. In discussing qualifications, this paper is concerned with arrangements for recognising students' achievements (outcomes). The processes of learning and teaching, which may lead to achievement, are different matters and not within the scope of this paper. (New Zealand Government, 1997, p. 2)

The rather narrow focus on qualifications, rather than on teaching and learning, is acceptable as long as recognition is given to the inextricable link between process and outcome, a point not recognised in the Green Paper. Furthermore, the document states: "The key element is quality..." (p. 10) without any comment on the fundamental importance of teaching and learning for educational quality. Quality within the document is largely defined in terms of meeting benchmarks for approving and specifying the components and outcomes of qualifications. But the literature on quality in education takes a far more comprehensive view than this. Harvey et al. (1992), for example, identify a number of conceptions of quality. These include:

- quality as exceptional (e.g., a focus on the distinctiveness of a programme or the achievement of outcomes which demonstrate excellence);

- quality as meeting minimum standards of achievement or approval (e.g., passing a unit standard or meeting NZQA approval criteria for offering a provider degree);

- quality as perfection (e.g., a focus on getting things right first time or on achieving zero defects; such criteria would apply to systems within institutions for recording student information);

- quality as fitness for purpose (e.g., meeting objectives related to the academic purposes of a programme);

- quality as value for money (e.g., meeting government criteria for accountability and efficiency in the use of public funding);

- quality as transformation (e.g., evidence that a programme has resulted in significant changes in student learning).

The final concept of transformation is the one which most educationists would claim to pay closest attention to. This is not to say that other definitions are not important or do not co-exist with the conception of quality as transformation. But it is difficult to see where transformation fits within the Green Paper proposals. Transformation is more than the specification of outcomes or meeting minimum benchmark criteria: it requires monitoring procedures which focus on the factors which provide evidence of significant changes in student learning. This requires a much greater focus on the systems that institutions use themselves for monitoring the educational experiences of their students. Procedures such as academic audit provide a suitable mechanism for both monitoring and promoting institutional self-development in matters related to teaching and learning (Hall, 1996). In this respect, the Green Paper has failed to acknowledge significant developments in quality monitoring that have taken place in recent years within the New Zealand tertiary sector. These developments have more potential for fostering genuine transformation than the registration criteria provided by the Green Paper.

\section{(vi) Decentralisation within the NQF}

One of the key features of educational reform over the past decade within New Zealand has been the twin emphasis on "decentralisation" - giving more control to the consumer-and "accountability" - requiring those vested with public money to account centrally for their use of such money. In respect of the NQF it has become very clear that the current structure, while giving greater focus to the accountability dimension through its various registration, approval and accreditation procedures, has failed in at least two important ways to achieve genuine decentralisation to consumers. First, the unit standard methodology is in fact a highly centralised system of recording information about the knowledge and skills that learners should demonstrate in respect of the training and education they receive. The sheer volume of information that potentially could be registered, and the relatively unresponsive nature of the system for dealing with changes to knowledge and practice, is in fact a significant threat to the Government's own Skill New Zealand strategy. The issue is not about industry-led training: it is about the mechanisms by which such a policy has been implemented and the inflexibility of the central structure. Secondly, it is difficult to see how the principal consumers of education and training - the learners - have achieved genuine power under the current system.

There are at least three ways in which learners might be given power in the present educational context. The first is through gaining greater access to education. Underpinning the initial development of 
the NQF were a number of suppositions about mechanisms which would aid such access. These included the implementation of standards-based education, the development of systems for fostering credit transfer and the recognition of prior learning, and the creation of multiple pathways to qualification attainment. In fact all of these mechanisms, while having obvious virtue, do not tackle the real problem of access to education, namely, the social stratification that underpins New Zealand society and the complex of factors (e.g., ethnicity, unequal distribution of wealth, intellectual variation) which relate to this. In as far as a national system of education can address these problems, the greatest impact is likely to occur through reform and innovations that are introduced well before the senior secondary school and tertiary levels of education. The NQF has limited scope for making a qualifications system accessible to more people, because it is influenced by deficiencies that lie outside its sphere of operation.

A second mechanism for providing students with power is through the provision of greater choice in programmes of study and better information about what is available and how to access that information. In this respect the Green Paper proposals that focus on outcomes, quality and qualification registration are likely to have some impact and therefore deserve careful consideration. But clarity of information, rather than the form in which that information is presented, is more important for helping students make sound decisions. Student advisory services and programme publications provided by individual institutions are more likely to help students make informed decisions than a central (NQF) register of qualifications and programmes, a point also made in the submission by Woodhouse (1997). The following extract from the NZVCC submission adds a further dimension:

We believe that some of the benefits claimed for the Framework in the Green Paper are dubious.... the Framework avowedly serves the purpose of informing potential users. But in this regard technology has superseded it. All tertiary institutions have, or soon will have, pages on the Internet, and all potential users have access to the Internet. The Internet is inclusive, cheap, international, comprehensive and responsive (in that it can be updated easily). The Framework suffers by comparison. (NZVCC, 1997)

The benefits of decentralisation are at the heart of the point being made by the NZVCC. The best place to locate detailed information about programmes and courses - their objectives/outcomes, content, assessment and delivery methods - is at the institutional level, not within a centralised qualifications framework. The former is responsive to change and places students in direct contact with the providers of the teaching; the latter is far less responsive and channels limited resources into unproductive activity. The following basic principle for approving NQF qualifications is consistent with the general direction, if not the actual detail, being proposed by the Green Paper:

... that registration of qualifications should involve the minimum of information needed to explain what a qualification is about, its structure, and who it is for; and that the information registered

should be at a level of detail where what is recorded will not need frequent amendment. (Hall, 1996, pp. 271)

The third mechanism for providing power to students lies in the adoption of teaching and learning processes which foster genuine "transformation". A more comprehensive coverage is provided by Meade (1997) in a discussion of the key challenges facing universities - quality, leadership and the management of change. Transformation is most likely to flourish in an environment where diversity and innovation in course design, delivery and assessment are encouraged.

From the perspective of institutional quality management, attention should be placed on systems which ensure that the key factors which contribute positively to student learning are monitored - clarity of course and assessment information, a focus on the needs of students, rapport between students and teachers, variety in teaching approaches, and assessment practices which foster in-depth understanding. The quality audit of educational institutions should thus include a strong focus on the extent to which student learning is central to the self-monitoring undertaken by institutions. It is hard to see how the proposals in the Green Paper will make any difference to the existing practices of institutions, both in respect of the quality of the education that they provide and the monitoring they undertake to enhance that quality.

\section{Two Further Issues}

There are two further issues addressed by the Green Paper which are problematic, one for universities and the other for school-based general education. 


\section{Loss of statutory authority}

The universities' position on membership of the NQF has never been more than lukewarm. In its response to the Tertiary Action Group consultation process, the NZVCC through its Committee on University Academic Programmes (1996) identified five broad concerns which would need to be met in order for it to register qualifications with the NQF:

- membership should not impair the international credibility of the universities;

- membership should not threaten the independence and autonomy of the universities;

- membership should not require universities to adopt the unit standard methodology;

- membership should not involve conformity to centralised requirements which would impinge on innovation and change;

- membership should involve the absolute minimum in devolved costs to the universities.

While pressure to use the unit standard model has been removed by the Green Paper, concerns remain in respect of each of the other criteria. These are fully discussed in the universities' submission (NZVCC, 1997); only the second will be dealt with here.

The Green Paper recommends assigning NZQA the role of overall guardian of the quality of NQF qualifications, and in respect of this role, NZQA is given the authority to delegate the approval of qualifications to appropriate agencies. Under these proposals, NZVCC would receive delegated authority to act as an NQF approval agency. This represents a significant shift from existing structures and seems to have merit only in respect of making the overall structure of the NQF look tidy. However, the universities quite rightly see the proposed structure as a significant threat to their autonomy. Currently the NZVCC's power to approve and accredit is a statutory right. This right derives from a more fundamental consideration, namely, that there must be institutions in any society - the media and institutions of higher learning are examples - which are free from government intrusion and control. This does not mean that universities can ignore the needs of the wider society and simply teach anything they want. This point is well recognised by the universities, and given effect through their voluntary compliance with approval criteria jointly developed by NZVCC and NZQA. Acceptance of these criteria ensures that the universities adopt a socially responsible attitude without having to surrender control to an external government agency. However, under the Green Paper proposal, there are several potential threats to such autonomy: the universities would be subject to any educational philosophy currently in vogue at NZQA (recent history suggests that this is a serious risk); they would be bound by subsequent changes to approval criteria and processes which could place unacceptable restrictions on the content and delivery of new and existing programmes; they would almost certainly become locked into a more expensive range of approval requirements with no proven benefit in terms of the quality of education being provided; and they would be subject to the threat that if they did not conform to the new "standard" for approving qualifications, their delegated authority could be withdrawn. Quite simply, there is no need for the government to create a situation where one fundamental principle - the freedom of universities to advance and/or challenge accepted knowledge through their teaching and research - should be placed in direct conflict with another principle - that consumers should be assured of the quality of the education that they receive. The two are able to co-exist at the moment. Why change this situation? What would be the benefits?

\section{Secondary school qualifications}

The final issue relates to the proposals on secondary school qualifications. The apparent intention of the proposals is to allow schools to choose between two philosophies of education - a standards-based approach as determined by unit standards, and a norm-referenced approach as determined by external examinations. The dichotomy presented by these proposals is potentially very damaging to school-based education. It assumes that standards-based education and norm-referenced education are independent, and that standards-based education equates with the unit standard methodology. The group of 15 secondary schools referred to above have developed a trial syllabus in English which, once extended to the seventh form, would include both internal and external assessment components, and give emphasis to standards-based assessment without adopting the unit standard methodology. Coherence and manageability are intended features of this programme, as is the intention to encourage and recognise excellence. The Green Paper proposals seem unlikely to allow for such a comfortable blend. The probable outcome will be a social stratification of schools, with some opting predominantly into a framework based on 
unit standards, and others predominantly into external examinations. The latter group of schools will predictably turn out the winners, and more and more parents will seek to send their children to them. Schools could well offer unit standards in conjunction with industry as part of employment or pre-employment training, but the model is inadequate for dealing with most areas of general education. To allow schools to be divided on social lines, simply because of the acceptance of a particular methodology of standard setting, is unsound. The problems with the unit standards model are both educational and administrative, and are likely to be compounded, rather than resolved, by the proposals in the Green Paper.

The very useful Post-Primary Teachers' Association Report on the NQF (1997) concludes by offering seven scenarios for taking secondary school qualifications forward. These options range from being entirely unit standards-based to being entirely examinations-based. The preferred model of the writers (scenario 7) is to:

Implement the Framework at Years 12 and 13. Retire Sixth Form Certificate as soon as the Framework is ready for full operation at year 12. Retain the Universities Bursaries assessments with adaptations which allow them to be credited onto the Framework.

Retire School Certificate. (PPTA, 1997, p. 121)

Underpinning this scenario is a strong recommendation that unit standards be re-developed so that they: include recognition of merit and excellence; are larger in size (a minimum of four credits); are less detailed in respect of their requirements for content coverage; involve more realistic expectations in respect of re-assessment; and include improved models of moderation. Whilst these suggestions would clearly represent an improvement on the current model, they still do not appear to offer the benefits that an approach along the lines being used in the trial English programme provides. Course coherence, manageability and capacity to blend with external examinations would still be significant problems under the PPTA unit standard model. It is worth noting that if the universities adopted this model, with four credits being the expected size of each standard, around 40,000 unit standards would be generated across the system! It is worth noting that while scenario 7 is the official recommendation of the PPTA, sufficient opposition amongst teachers to the unit standard model exists to make it unlikely that such a system could be introduced "across the board".

\section{Implications and Way Forward}

The Green Paper does make a brave attempt to tread the middle ground. It has recognised the difficulties associated with the existing NQF, but has not really gone deeply enough into some of the underlying issues. The solution it proposes represents a patching-up a shift in focus from a "unit standards" framework to a "quality threshold" framework - rather than a fundamental rethink of what is needed. As the report on the NQF commissioned by the Education Forum states:

It has taken the cumulative resistance of many schools and the universities, lack of enthusiasm on the part of much of industry, and a change of minister to bring about some acceptance that the intended National Qualifications Framework is not working. However, the Green Papers clearly show that the government's advisers are still looking for another unifying concept to provide coherence and justify the NQF's continued existence. The new big idea is "quality threshold". However ... neither "unit standard" nor "quality threshold" is capable of delivering what is required of it. The uncomfortable message of this report is that there is no alternative to working through a whole range of issues and problems from first principles. (Smithers, 1997, p. 61)

The following list sets out some of the considerations arising from the preceding discussion and identifies concerns which a new qualifications structure will need to address. The list overlaps with many of the problems identified by Gilmore (1997) and Smithers (1997).

A new qualifications structure will need to recognise:

- that the personal, social and economic dimensions of education and training are closely linked;

- that the blending of general and vocational education cannot be forced by adopting the same approach to qualification specification, standard setting and assessment;

- that the different sectors (industry, secondary schools, universities and other tertiary providers) approach the education and training they provide from different perspectives, with different aims, different pedagogies and different organisational arrangements;

- that the different sectors should have the right to identify an approach to education and qualification specification which is 
appropriate to the needs of the different groups they serve, including the learners;

- that the unit standard model is generally unsuitable for general education and should be withdrawn from such contexts;

- that standards-based assessment should not be equated with the unit standard model:

- that standards-based education in a pure sense cannot be implemented, but greater emphasis can be given to such an approach by adopting sound assessment principles and practices;

- that the principles of coherence, manageability and flexibility should govern the development of educational programmes rather than a commitment to a narrowly-conceived national philosophy of education (i.e., outcomes-based education);

- that educational process and outcome are inextricably linked;

- that the open-ended nature of knowledge and learning cannot be captured with precision by a statement of outcomes;

- that purpose, structure and content come before portability and transfer in the design of educational programmes;

- that adoption of the Green Paper approval criteria of "credibility", "durability", " portability" and "structural soundness" provides only a limited conception of quality;

- that registration of qualifications on the framework should involve the minimum of information needed to explain the purpose, structure and broad assessment arrangements of the qualification; and that the devolved costs to participants should be held to the absolute minimum;

- that the principle of decentralisation in the provision of educational programmes should not be compromised by the accountability arrangements required of educational providers;

- that the autonomy of universities to approve their own programmes should not be compromised by structural arrangements of the framework;

- that arrangements for secondary school qualifications should not contribute to the social stratification of schools;

- that membership of a qualifications framework continues to remain voluntary.
The preceding considerations identify the need for a quite different structural arrangement for a qualifications framework than exists at present or is envisaged by the Green Paper. Perhaps more than anything else, successful implementation of a new structure will require greater mutual understanding than currently exists by the different sectors (industry, schools, universities and other tertiary providers) of each others' needs. Of the models suggested in publicly available responses to the Green Paper, the one proposed by Smithers (1997) comes nearest to dealing adequately with the above points. This model, described as a "qualifications network", recognises the different needs of schools, employment, universities and other degree providers, by giving each control over its own sector. Regulatory bodies are proposed within each of these sectors (the universities retaining their current mechanisms) with an overarching Qualification Co-ordinating Council being established to recommend policy, to ensure liaison between the sectors, and to maintain a national database of registered qualifications. While the model proposed by Smithers is still skeletal, it offers some hope that the principles of course coherence, flexibility, manageability and decentralisation can be realised. Government advisers should consider whether or not, in the long run, a major restructuring might be more productive and cost-effective than attempting to refocus the existing NQF along the lines envisaged in the Green Paper.

\section{References}

Academic Board of the Christchurch College of Education. (1997). Submission on the Government Green Paper: A futurequalifications policy for New Zealand.

$<$ http://www.minedu.govt.nz/data/NQF/subs/ chchcol.htm >

Barker, A. (1995). Standards-based assessment: The vision and broader factors. In R. Peddie \& B. Tuck, Setting the standards. Palmerston North: Dunmore Press.

Brace, J. (1996). The Qualifications Framework and standards-based assessment: A threat to quality learning in secondary schools. Wellington: Law Society.

Churchman, R. \& Hall, C. (1997). Unit standards and professional education: A question of compatibility. Victoria University of Wellington: University Teaching Development Centre, Academic Development Series. 
Codd, J., McAlpine, D. \& Poskitt, J. (1995). Assessment Policies in New Zealand: Educational reform or political agenda? In R. Peddie \& B. Tuck, Setting the standards. Palmerston North: Dunmore Press.

Codd, J. (1995). NZQA and the politics of centralism. Paper presented at the Annual Conference of the New Zealand Association for Research in Education, Massey University, Palmerston North, December 7-10.

Committee on University Academic Programmes. (1996). Tertiary Action Group: Universities' response to second draft of consultation papers. Wellington: New Zealand Vice-Chancellors' Committee.

Doyle, S. (1997). They're regrouping! The Framework and the challenges for open and distance learning. Paper presented to the national seminar held by the Distance Education Association of New Zealand: The Winds and Tides of Change. Wellington, August.

Elley, W. (1995). What is wrong with standards-based assessment? In R. Peddie \& B. Tuck, Setting the standards. Palmerston North: Dunmore Press.

Elley, W. (1996). Unresolved issues in fitting academic courses into the Qualifications Framework. Delta, 48(1), 101-112

Fitzsimons, P. \& Peters, M. (1994). Human capital theory and the government's industry training strategy. Journal of Education Policy, 9(3), 245-266.

Gilmore, A. (1997). New Zealand Literature Review. In Te Tiro Hou, Report of the Qualifications Framework Inquiry commissioned by the Post Primary Teachers' Association, Wellington.

Hall, A. (1997). Unit standards for New Zealand pre-service teacher education: Some questions for the universities. Hamilton: University of Waikato, School of Education.

Hall, C. (1994). Obstacles to the integration of university qualifications and courses into the National Qualifications Framework. Higher education in New Zealand: Occasional paper No. 1. Wellington: Syndicate of Educational Development Centres of New Zealand.

Hall, C. (1996). Blending academic standards with the New Zealand National Qualifications Framework: Lessons for other countries. In A. Strydom, L. Lategan, \& A. Muller (Eds.), Quality assurance in South African higher education: National and international perspectives. Bloemfontein: Unit for Research into Higher Education, University of the Orange Free State.
Hall, C. (1997). The National Qualifications Framework in 1996 and beyond: A call for reflection on the nature of outcomes-based education. New Zealand Annual Review of Education, 6, 71-87.

Harvey, L., Burrows, A. \& Green, D. (1992). Criteria of quality. Birmingham: Quality in Higher Education Project, The University of Central England in Birmingham.

Hawke, G. et al. (1988). Report of the working group on post compulsory education and training. Wellington: Government Printer.

Irwin, M. (1994). Curriculum, assessment and qualifications: An evaluation of current reforms. Wellington: Education Forum.

Irwin, M. (1997). The National Qualifications Framework: Where to now? New Zealand Business Roundtable. Paper given to the Waikato Forum on Education, University of Waikato, Hamilton, August 7.

Meade, P. H. (1997). Challenges facing universities: Quality, leadership and the management of change. Dunedin: University of Otago.

Murphy, B. (1997). Some factors relating to the training of automotive engineers. Unpublished Master of Education thesis, Victoria University of Wellington.

New Zealand Association of Private Education Providers. (1997). Submission on the Government Green Paper: A Future Qualifications Policy for New Zealand.

$<$ http://www.minedu.govt.nz /data /NQF/subs/nzapep.htm >

New Zealand Government. (1997). A future qualifications policy for New Zealand: A plan for the National Qualifications Framework (Green Paper). Wellington: Ministry of Education.

New Zealand Motor Industry Training Organisation. (1995). Annual Report to the Education and Training Support Agency and the Motor Industry. Wellington.

New Zealand Qualifications Authority. (1995, April). Learn.

New Zealand Vice-Chancellors' Committee. (1994). The National Qualifications Framework and the universities. Wellington: NZVCC.

New Zealand Vice-Chancellors' Committee. (1997). Submission on the Government Green Paper: A Future Qualifications Policy for New Zealand. < http://www.minedu.govt.nz/data/NQF/subs/nzvcc.htm>

Neyland, J. (1996). Outcomes-based mathematics education. Wellington: Victoria University of Wellington, Mathematics and Science Education Centre.

Neyland, J. (1997). Putting unit standards to the test? Wellington: Victoria University of Wellington, Mathematics and Science Education Centre. 
Post-Primary Teachers Association. (1997). Te Tiro Hou. Report of the Qualifications Framework Inquiry commissioned by the PPTA, Wellington.

Retail Training New Zealand (Inc.). (1997). Submission on the Government Green Paper: A Future Qualifications Policy for New Zealand. $<$ http://www.minedu.govt.nz/data/NQF/subs/rtnz.htm>

Rivers, J. (1996, September). ITOs have too much power, say tutors. New Zealand Education Review, 1(21), 1.

Smithers, A. (1997). The New Zealand Qualifications Framework. Wellington: Education Forum.

The New Zealand Institute of Travel \& Tourism (Inc.). (1997). Submission on the Government Green Paper: A Future Qualifications Policy for New Zealand. <http://www.minedu.govt.nz/data/NQF/subs/crocker.htm>

Tuck, B. (1995). Issues of objectivity in assessment: A plea for moderation. In R. Peddie \& B. Tuck, Setting the standards. Palmerston North: Dunmore Press.

Viskovic, A.R. (1993). Learning and competence: A critique of NZQA's perspective as evidenced by the unit standards requirements. In M. Parer (Ed.), Research and Development in Higher Education 15 (pp. 334-341). HERDSA.

Woodhouse, D. (1997). Response to the Green Paper: A future qualifications policy for New Zealand: A plan for the National Qualifications Framework. New Zealand Universities Academic Audit Unit, Wellington.

\section{The author}

Cedric Hall is Professor and Dean of Education at Victoria University of Wellington. He was formerly Director of the University Teaching Development Centre at the same university. His research interests include course design, teaching, learning, assessment and evaluation. Some of his recent papers have included a focus on quality assurance in higher education and developments in the National Qualifications Framework. 